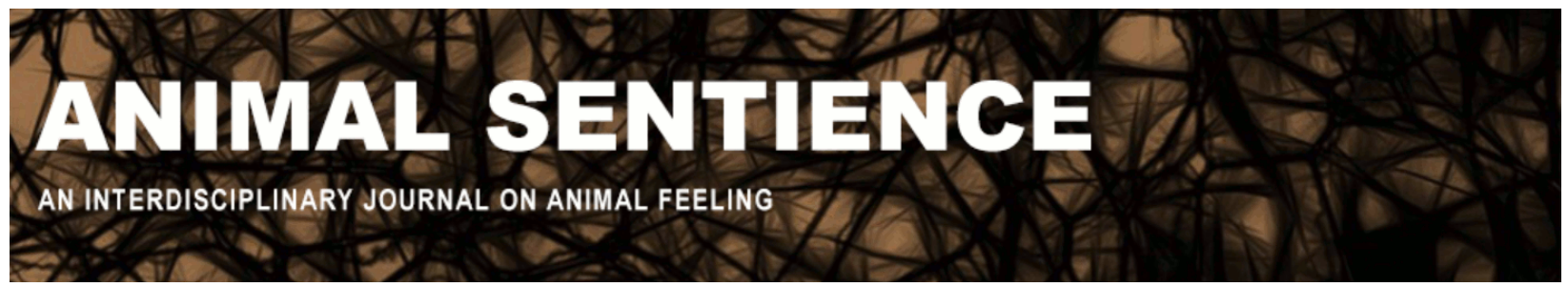

Editorial: Balcombe, Jonathan (2017) Tribute to Jaak Panksepp.

DOI: $10.51291 / 2377-7478.1212$

Date of submission: 2017-09-21

Date of acceptance: 2017-10-03

(c) (i)

This article has appeared in the journal Animal

Sentience, a peer-reviewed journal on animal

cognition and feeling. It has been made open access,

free for all, by WellBeing International and deposited

in the WBI Studies Repository. For more information,

please contact

wbisr-info@wellbeingintl.org.

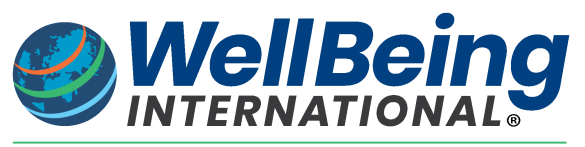

SOLUTIONS FOR PEOPLE, ANIMALS AND ENVIRONMENT 


\section{Tribute to Jaak Panksepp}

June 5, 1943 - April 18, 2017

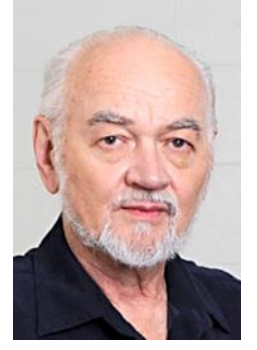

by Jonathan Balcombe

It was with sadness that I learned the news of Jaak Panksepp's death from cancer on April 18. With his passing, the world lost not just a gifted scientist, but also a kind man always willing to share his precious time.

I first discovered Panksepp's work in 2003 while researching a book on animal pleasure. How delightful it was to find that a neuroscientist - a member of a discipline not noted for being friendly to animals - had unveiled compelling evidence that rats experience mirthful emotional states analogous to human laughter. Combining behavioral studies with brainimaging techniques, Panksepp built a rock-solid case to support a thesis that few scientists would have even courted, let alone pursued.

Not surprisingly, the radical idea that rats laugh drew resistance. Panksepp's many requests for funding to explore the phenomenon went largely unrewarded. Undaunted, he funded it himself. When a pair of neuroscientists questioned Panksepp's interpretation that ultrasonic rat vocalizations expressed positive (and negative) emotions, arguing instead that these calls were "analogous to a sneeze, serving a physiological function while incidentally producing sound," Panksepp published a diplomatic but forceful rebuttal.

Neuroscience was never my strong suit, and I was soon emailing Jaak with questions. He was as helpful a correspondent as he was a prolific scientist. Living at the time in England, I was invited by Jaak to attend a lecture he gave in Leicester. He kindly reviewed a draft chapter that referenced his rat studies. Two years later, I spoke on a panel Jaak organized at a conference titled "Toward a Science of Consciousness" in Tucson. I last saw Jaak in 2014 when he spoke at a conference on animal sentience organized by my colleagues and me in Washington, DC.

While he is best known for his studies of rat mirth (a National Geographic segment has garnered over four million YouTube views), it was part of a broader canon of work that advanced our understanding and appreciation of emotions. His 1998 book Affective Neuroscience is a classic that continues to influence (and legitimize) a new generation of scientists studying subjective experience in animals. Much of Jaak's work was framed in the cause of improving the well-being of humans and nonhuman animals. He is well-known for outlining the possible role of the brain's opiate system in the etiology of autism. In 2004, Panksepp received an honorary doctorate from the University of Tartu in his native Estonia.

Such are his contributions that time will probably be kind to Jaak Panksepp's legacy. He hasn't even finished publishing: The Emotional Foundations of Personality, co-authored with Ken Davis, is scheduled for release in March 2018.

Panksepp, J. (1982) Toward a general psychobiological theory of emotions. Behavioral and Brain Sciences 5(3): 407-422.

Panksepp, J. (2016) Brain processes for "good" and "bad" feelings: How far back in evolution? Animal Sentience 3(24). 